OPEN ACCESS

Edited by:

David Rodriguez-Lazaro,

University of Burgos, Spain

Reviewed by:

Lee-Ann Jaykus,

North Carolina State University,

United States

Dan Li,

Ghent University, Belgium

${ }^{*}$ Correspondence:

Peng Tian

peng.tian@ars.usda.gov

Specialty section:

This article was submitted to

Food Microbiology,

a section of the journal

Frontiers in Microbiology

Received: 05 June 2017

Accepted: 28 August 2017

Published: 21 September 2017

Citation:

Li $Q$, Wang $D$, Yang $D$, Shan $L$ and Tian P (2017) Binding of Escherichia coli Does Not Protect Tulane Virus from Heat-Inactivation Regardless

the Expression of HBGA-Like

Molecules. Front. Microbiol. 8:1746. doi: 10.3389/fmicb.2017.01746

\section{Binding of Escherichia coli Does Not Protect Tulane Virus from Heat-Inactivation Regardless the Expression of HBGA-Like Molecules}

\author{
Qianqian Li',2, Dapeng Wang ${ }^{3}$, David Yang ${ }^{2}$, Lei Shan ${ }^{2}$ and Peng Tian ${ }^{2 *}$ \\ ${ }^{1}$ Department of Bioengineering, Shanghai Institute of Technology, Shanghai, China, ${ }^{2}$ Produce Safety and Microbiology \\ Research Unit, Western Regional Research Center, Agricultural Research Service, United States Department of Agriculture, \\ Albany, CA, United States, ${ }^{3}$ MOST-USDA Joint Research Center for Food Safety, School of Agriculture and Biology, \\ Shanghai Jiao Tong University, Shanghai, China
}

Histo-blood group antigens (HBGAs) are considered as receptors/co-receptors for human norovirus (HuNoV). It has been reported that binding of HuNoV-derived viruslike particles (VLPS) to HBGA-like molecules-expressing bacteria increased the stability of VLPs to heat-denaturation (HD). In this study, we tested for HBGA-like-bindingconveyed protection against HD on viral replication using Tulane virus (TV) and Escherichia coli $\mathrm{O} 86: \mathrm{H} 2(\mathrm{O} 86: \mathrm{H} 2)$, with E. coli $\mathrm{K}-12$ (K-12) used as a control. Expression of HBGA type B was confirmed by ELISA in O86:H2 but not in $\mathrm{K}-12$. Binding of TV was confirmed by ELISA in O86: $\mathrm{H} 2(\mathrm{P} / \mathrm{N}=2.23)$ but not in $\mathrm{K}-12(\mathrm{P} / \mathrm{N}=1.90)$. Preincubation of TV with free HBGA could completely inhibit its ability to bind to $086: \mathrm{H} 2$ $(p=0.004)$, while producing no significant change in its ability to bind $\mathrm{K}-12(p=0.635)$. We utilized a bacterial-capture-RT-qPCR procedure to confirm that both bacterial strains were capable of binding TV, and that O86: $\mathrm{H} 2$ exhibited fivefold greater binding capacity than K-12. Pre-incubation of TV with free HBGA would partially inhibit the binding of TV to 086:H2 $(p=0.047)$. In contrast, not only did pre-incubation of TV with free HBGA not inhibit the binding of TV to $K-12$, binding was slightly enhanced $(p=0.13)$. The viral infectivity assay allowed us to conduct a direct evaluation of the ability of HBGAlike-bound bacteria to confer HD protection to TV. Prior to inoculate to LLC-MK2 cells, TV was incubated with each bacterial strain at ratios of 1:0, 1:1 and 100:1, then both partially and fully HD. The viral amplification was quantitated by RT-qPCR $48 \mathrm{~h}$ later. The binding of bacteria to TV reduced viral replication in a dose-dependent matter. We found that neither bound $\mathrm{O} 86: \mathrm{H} 2$ nor $\mathrm{K}-12$ conferred protection of TV against partial or full HD conditions. Partial HD reduction of viral replication was not significantly impacted by the binding of either bacterial strain, with infectivity losses of 99.03, 99.42, 96.32, 96.10, and 98.88\% for TV w/o bacteria, TV w/O86:H2 (1:1), TV w/O86:H2 (100:1), TV w/K-12 (1:1), and TV w/K-12 (100:1), respectively. Full HD reduction of viral replication was not impacted by the binding of either bacterial strain, as full loss of infectivity was observed in all cases.

Keywords: norovirus, histo-blood group antigens, Tulane virus, Escherichia coli, heat-denaturation, protection, ELISA, RT-qPCR 


\section{INTRODUCTION}

Human noroviruses (HuNoVs) are the major cause of outbreaks of acute non-bacterial gastroenteritis. Noroviruses have a singlestranded, positive-sense RNA genome which contains three open reading frames (ORFs) encoding non-structural proteins (ORF1), a capsid protein VP1 (ORF2), and a minor capsid protein VP2 (ORF3) (Xi et al., 1990; Jiang et al., 1993; Hardy, 2005). HuNoVs are difficult to grow in cell culture, and culturable viruses such as Tulane virus (TV), murine norovirus (MNV), and feline calicivirus (FCV) are often utilized as surrogates for studying the fundamental biology of $\mathrm{HuNoV}$, such as viral replication pattern, and mechanism of infection (Cannon et al., 2006; Wobus et al., 2006; Farkas et al., 2008; Tian et al., 2013).

The relationship between histo-blood group antigens (HBGAs) and susceptibility to $\mathrm{HuNoV}$ infections was noticed by several research groups (Parrino et al., 1977; Gary et al., 1987). HBGAs can be either lipid-linked or proteinlinked, and can present as either membrane-associated or secreted. HuNoVs were found to interact with cell-surfacedisplayed HBGAs, and were thought to be important for viral infection (Harrington et al., 2002; Huang et al., 2005). Although most HuNoVs preferentially bind to one-or-more HBGAs, some norovirus genotypes do not bind or poorly bind HBGAs (Tan and Jiang, 2005). TV binds to type-A and type-B HBGAs (Farkas et al., 2010). Surrogate viruses also bind to molecules other than HBGAs. MNV-1 and FCV bind to sialic acid (Stuart and Brown, 2007; Taube et al., 2009).

An early study demonstrated that enteric bacteria can enhance poliovirus replication in vivo and in culture (Kuss et al., 2011). It has been hypothesized that bacterial components might increase viral receptor binding or viral shedding. HBGA-like moieties have been reported to be present on the surface of some enteric bacteria (Springer et al., 1961; Yi et al., 2006; Miura et al., 2013; Li et al., 2015). Interactions between bacterial-expressed HBGA-like molecules and HuNoV/surrogates and their role in viral replication and resistance/survival have been investigated recently. $\mathrm{HuNoV}$ was found to bind specifically to the type H HBGA that could be found on Enterobacter cloacae (Miura et al., 2013). Li et al. (2015) reported that HuNoV virallike particles (VLPs) bound to HBGA-like molecules-expressing bacteria. Almand et al. (2017) recently reported that HuNoV and TV were able to bind to both Gram-positive and negative bacteria selected from human gut microbiota, with TEM showing that the viruses could be found bound to the bacterial outer cell membrane, intestinal pili, or both. The interaction between $\mathrm{HuNoV} /$ surrogates and bacteria seemed specific as Turnip Crinkle virus, a plant virus that closely resembles HuNoV and was used as a control, did not bind to these bacteria (Almand et al., 2017). However, there was no evidence that these tested bacteria all expressed HBGA-like molecules, and therefore remains unclear if bacterial molecules other than HBGA are involved in the binding of the viruses.

The exact role HBGA-like-expressing bacteria play in the lifecycle of enteric viruses and norovirus remains unknown. Jones et al. (2014) demonstrated that the infection of B cells by MNV was promoted by Enterobacter cloacae expressing type-H HBGAlike molecules or synthetic HBGA. Karst and Wobus (2015) proposed that HBGA-like molecules-expressing bacteria might help $\mathrm{HuNoV}$ and MNV to transcytose across intestinal epithelial cells. Robinson et al. (2014) reported that the environmental stability and target cell attachment of poliovirus was enhanced by the binding of bacterial surface polysaccharides. Li et al. (2015) recently reported that the binding of HBGA-like moleculesexpressing bacteria to HuNoV VLPs increased the ability of the viral capsids to resist heat denaturation. Although the study suggests that the binding of HBGA-like molecules-expressing bacteria protected HuNoV VLPs from heat denaturation, it does not extend to drawing conclusions concerning the potential for HBGA-like molecules-expressing bacteria to protect $\mathrm{HuNoV}$ from heat-denaturation-related reduction of infectivity. In this study, we used TV as a surrogate to test the impact of HBGAlike molecules-expressing bacteria on viral infectivity after heat treatment.

Tulane virus is a calicivirus isolated from stools of rhesus macaques at the Tulane National Primate Research Center (Farkas et al., 2008). TV replicates in vitro in rhesus monkey kidney immortal cell culture (LLC-MK2) and causes typical cytopathic effect (CPE). TV recognizes both type-A and type-B HBGAs and receptors for infection, preferring the latter (Farkas et al., 2010). The virus could be partially inactivated at $50^{\circ} \mathrm{C}$ for $10 \mathrm{~min}$. and completely inactivated at $56^{\circ} \mathrm{C}$ for $30 \mathrm{~min}$ (Tian et al., 2013). For this study, E. coli $\mathrm{O} 86: \mathrm{H} 2$ was selected for its ability to express type-B HBGA-like molecules (Yi et al., 2006). The viral replication was measured by a newly developed cellculture-mediated amplification RT-qPCR assay (Xu et al., 2015).

\section{MATERIALS AND METHODS}

\section{Sources and Preparation of Bacteria, Virus, Saliva, and Reagents}

Tulane virus (TV) was kindly provided by Dr. Jiang (Division of Infectious Diseases, Cincinnati Children's Hospital Medical Center, Cincinnati, $\mathrm{OH}$, United States), and viral cultured in LLC-MK2 (American Type Culture Collection, Manassas, VA, United States) cell culture (Tian et al., 2013). E. coli O86:H2 and K-12 were kindly provided by Dr. Wang (Peng G. Wang, Department of Chemistry, Georgia State University, Atlanta, GA, United States). Bacterial strains were cultured in $5 \mathrm{~mL}$ aliquots of LB medium at $37^{\circ} \mathrm{C}$, at moderate mixing $(200 \mathrm{rpm})$ for overnight. The cultured bacteria were pelleted by centrifugation $(8,000 \mathrm{RCF}$ for $2 \mathrm{~min}$ ), and the bacterial pellet was washed three times by vortex re-suspension with PBS and re-pelleted by centrifugation to produce working stocks of media-free cell suspensions.

Human saliva was sourced from three blood-type B volunteers under approval by the Institutional and Location Bio-safety Committees (IBC and LBC) of Shanghai Jiao Tong University, Institutional Ethics Committees (IEC) of College of Agriculture and Biology, Shanghai Jiao Tong University, and written informed consent was obtained from the volunteers. With no personal information collected, about $2 \mathrm{ml}$ saliva was collected from each volunteer, immediately aggregated, then mixed. The 
mixed saliva was boiled for $5 \mathrm{~min}$, then centrifuged at $10,000 \times g$ for $5 \mathrm{~min}$. The clarified supernatant was aliquotted and stored at $-20^{\circ} \mathrm{C}$ (Wang et al., 2017).

Monoclonal antibodies (MAbs) against blood group antigenprecursor "H” (“BG1"), type A (“BG2"), type B (“BG3"), H1 (“BG4"), Lewis a (“BG5”), Lewis b (“BG6”), Lewis x (“BG7”), and Lewis y ("BG8") were purchased from a commercial source (BioLegend, Inc., San Diego, CA, United States). AP-conjugated goat anti-mouse IgM and IgG; and AP-conjugated goat antirabbit IgG were purchased from a commercial source (ZYMED Laboratories, South San Francisco, CA, United States). Rabbitanti-TV sera was kindly provided by Dr. Jiang (Division of Infectious Diseases, Cincinnati Children's Hospital Medical Center, Cincinnati, OH, United States). Type III porcine gastric mucin (PGM) was purchased from a commercial source (Sigma, St. Louis, MI, United States).

\section{Detection of HBGA Present in Bacteria by ELISA}

Both E. coli $\mathrm{O} 86: \mathrm{H} 2$ and K-12 media-free bacterial suspensions were adjusted with PBS to an $\mathrm{OD}_{600}$ of 0.1 . Each $\mathrm{OD}_{600}$ 0.1 bacterial suspension was seeded into individual wells of immunoassay strips (Nunc Immuno Modules, Thermo, MA, United States). Well were air-dried. Each well was subsequently rinsed three times with PBS, then air-dried. To block unbound well surfaces, $200 \mu$ l of $10 \%$ skim milk (Difco Laboratories, Detroit, MI, United States) in PBS was added to each well and incubated at $37^{\circ} \mathrm{C}$ for $2 \mathrm{~h}$, then carefully removed and rinsed once with PBS. The commercial stocks of the MAbs were diluted 1:50 in PBS and added into each well and incubated at $37^{\circ} \mathrm{C}$ for $1 \mathrm{~h}$. Unbound MAbs were removed by washing wells three times with $250 \mu \mathrm{l}$ of TBS containing $0.5 \%$ Tween-20 (TBST). One hundred $\mu$ l of goat anti-mouse IgG (MAbs BG2, 4, and 5) or goat anti-mouse IgM (MAbs BG1, 3, 6, 7, and 8) conjugated to alkaline phosphatase (AP) and diluted 1:3000 in TBST were added to appropriate wells, and the wells were incubated at $37^{\circ} \mathrm{C}$ for $1 \mathrm{~h}$, followed by three washes with $250 \mu \mathrm{l}$ of TBST. The presence of well-bound bacteria-and-alkalinephosphatase-conjugated-antibody complex was developed for detection by the addition of $100 \mu \mathrm{l}$ of alkaline phosphatase substrate [ $p$-nitrophenyl phosphate, disodium salt substrate at a concentration of $1.0 \mathrm{mg} / \mathrm{ml}$ in diethanolamine substrate buffer (Pierce, Rockford, IL, United States)] to each well. The color reaction is quantitated using a spectrophotometric plate reader (Spectramax ELISA reader, Molecular Devices, Sunnyvale, CA, United States) reading absorbance at $405 \mathrm{~nm}$. E. coli K-12 was used as a control for non-specific binding. The $\mathrm{P} / \mathrm{N}$ ratio was calculated using OD readings from wells omitted for primary antibodies as $\mathrm{N}$.

\section{Detection of TV Binding to Bacteria by ELISA}

To reduce the non-specific antibody binding of E. coli, Rabbitanti TV antiserum was pre-absorbed with E. coli K12 extract. Briefly, E. coli K-12 media-free bacterial suspension was adjusted to $\mathrm{OD}_{600}$ of 0.1 , and then lysed by ultrasonication (Qsonica
Sonicator Q500, Fisher Scientific, United States) using 4-s bursts at 6-s intervals for $10 \mathrm{~min}(225 \mathrm{~W})$ on ice. The cell lysate was clarified by centrifugation at $12,000 \times g$ at $4^{\circ} \mathrm{C}$ for $10 \mathrm{~min}$, and the supernatant was collected. Rabbit-anti TV antiserum was diluted into the supernatant at a ratio of 1:100 and incubated at $37^{\circ} \mathrm{C}$ for $30 \mathrm{~min}$. The supernatant w/antiserum was centrifuged at $12,000 \times g$ at $4^{\circ} \mathrm{C}$ for $10 \mathrm{~min}$, and the supernatant was collected and stored at $4^{\circ} \mathrm{C}$ for further use.

Immunoassay plates were coated with bacteria and blocked with skim milk as described in the previous section. Free HBGA for receptor competition was made from mixing PGM $(1.0 \mathrm{mg} / \mathrm{ml})$ and type $B$ saliva at a ratio of 10:1. Ninety microliters of TV stock were incubated with $10 \mu \mathrm{l}$ of either free HBGA or PBS (as a control) and incubated at $37^{\circ} \mathrm{C}$ for $1 \mathrm{~h}$. The TV stock w/free HBGA were then added to the coated-andblocked wells, and incubated at $37^{\circ} \mathrm{C}$ for $1 \mathrm{~h}$. Viral stock was carefully removed, and residual stock was removed from the wells by rinsing three times with PBS. Primary antibodies were introduced with the addition of $100 \mu$ l of diluted (1:3000 in $\mathrm{PBS}$ ) rabbit-anti-TV antiserum to each well, incubation at $37^{\circ} \mathrm{C}$ for $1 \mathrm{~h}$, then carefully removed. Residual, unbound primary antibodies were removed from the wells by rinsing three times with TBST. Secondary antibodies were introduced with the addition of $100 \mu \mathrm{l}$ of diluted (1:10,000 in TBST) AP-conjugated goat anti-rabbit IgG to respective wells, and incubated at $37^{\circ} \mathrm{C}$ for $1 \mathrm{~h}$. Residual, unbound secondary antibodies were removed from the wells by rinsing three times with TBST. The presence of well-bound bacteria-TV-and-alkaline-phosphataseconjugated-antibody complex was developed as described in the previous section, as was the use of E. coli K-12 as a control for non-specific binding. The $\mathrm{P} / \mathrm{N}$ ratio was calculated using $\mathrm{OD}$ readings from wells omitted for primary antibodies as $\mathrm{N}$.

\section{Binding of TV to Bacteria Measured by RT-qPCR}

Both E. coli O86:H2 and K-12 media-free bacterial suspensions were adjusted with PBS to approximately $10^{8} \mathrm{CFU} / \mathrm{ml}$. Free HBGA stock was made from a mixture of PGM $(1.0 \mathrm{mg} / \mathrm{ml})$ and type B saliva at a 10:1 ratio. Ninety microliter aliquots of TV stock were incubated with either $10 \mu \mathrm{l}$ free HBGA stock or PBS (as control) at $37^{\circ} \mathrm{C}$ for $1 \mathrm{~h}$. One hundred microliters of each bacterial strain was added to the free HBGA-incubated TV stock aliquots, and incubated at $37^{\circ} \mathrm{C}$ and $50 \mathrm{rpm}$ for $1 \mathrm{~h}$. Bacteria were recovered from solution by centrifugation at $12,000 \mathrm{RCF}$ for $1 \mathrm{~min}$. The bacterial pellet was washed three times by vortex re-suspension with PBS and re-pelleted by centrifugation, and finally re-suspended into $140 \mu \mathrm{l}$ of PBS. Viral RNA was extracted from bacteria-bound TV using a commercial viral RNA extraction kit ("QIAamp RNA Viral Mini," Qiagen, Valencia, CA, United States) in accordance with the manufacturer's protocol. Primers and probes were synthesized with modified fluorophores and quenchers (Integrated DNA Technologies, Inc.; San Diego, CA, United States). The primers and probes used for detection of TV were: TV forward ( $5^{\prime}$-TGA CGA TGA CCT TGC GTG-3'), TV reverse (5'-TGG GAT TCA ACC ATG ATA CAG TC-3'), TV probe (5' HEX- ACC CCA 
AAG CCC CAG AGT TGA T -BHQ-1 3'). Extracted viral RNA was quantitated by probe-based quantitative real-time RT-PCR using a one-step RT-qPCR kit ("Quantitect Probe RT-PCR Kit," Qiagen, Valencia, CA, United States) scaled to half-reaction volumes, but otherwise in accordance with the manufacturer's protocol. Each $25 \mu \mathrm{l}$ reaction consisted of $12.5 \mu \mathrm{l}$ of Quantitect Probe RT-PCR master mix, $7.5 \mu$ l of RNAse-free water, $0.75 \mu \mathrm{l}$ of each primer (TV forward, TV reverse, both at $10 \mu \mathrm{M}$ ), $0.25 \mu \mathrm{l}$ of TV probe at $10 \mu \mathrm{M}, 0.25 \mu \mathrm{l}$ of Quantitect RT mix, and $3 \mu \mathrm{l}$ of extracted RNA. Cycling times and temperatures were $50^{\circ} \mathrm{C}$ for $30 \mathrm{~min}$ (reverse transcription), $95^{\circ} \mathrm{C}$ for $15 \mathrm{~min}$ (denaturation of reverse transcriptase, and activation of Taq polymerase), followed by 45 cycles of $95^{\circ} \mathrm{C}$ for $15 \mathrm{~s}, 53^{\circ} \mathrm{C}$ for $20 \mathrm{~s}$, and $60^{\circ} \mathrm{C}$ for $50 \mathrm{~s}$ (thermal cycling). Fluorescence was read at the end of each $60^{\circ} \mathrm{C}$ extension step. Automated thermal cycling and data acquisition was performed on a MX3000P qPCR system and MxPro software (Stratagene; La Jolla, CA, United States), with threshold determination at default settings. TV and RNase-free $\mathrm{ddH}_{2} \mathrm{O}$ were used as positive control and negative control, respectively. Unitless $\mathrm{Ct}$ values represented the viral genomic signal, which was converted to genomic copies by a recombinant-plasmid-based standard curve (Tian et al., 2013). The experiments in comparison with each other were done on the same plate with known amount TV viral RNA used as an internal standard.

\section{Partial and Full Heat-Inactivation for TV}

TV stock was incubated with E. coli O86:H2, K-12, and PBS (as a control) at ratios of 1:1 and 100:1 at room temperature for $1 \mathrm{~h}$. Three hundred microliter aliquots of TV-E. coli stock in $1.5-\mathrm{ml}$ microcentrifuge tubes were heat-denatured at partial $\left(56^{\circ} \mathrm{C}\right.$ for $\left.10 \mathrm{~min}\right)$ or full $\left(56^{\circ} \mathrm{C}\right.$ for $\left.30 \mathrm{~min}\right)$ inactivation conditions, and quickly cooled in ice water bath. The control samples were kept at room temperature (Wang et al., 2014).

\section{Detection of Viral Infectivity by Culture-Mediated-Amplification RT-qPCR Assay (CMA-RT-qPCR)}

CMA-RT-qPCR assay was used to determine infectivity of TV (Xu et al., 2015). Briefly, 24-well tissue culture plates (Corning Corporation, Corning, NY, United States) were seeded with LLC-MK2 cells in CMEM and incubated overnight to reach 80-90\% confluency. CMEM was carefully removed from each well, $100 \mu \mathrm{l} /$ well of TV stock, TV-bacteria complex, and heatdenatured versions of the prior was added, and incubated at $37^{\circ} \mathrm{C}$ for $1 \mathrm{~h}$. Media was then carefully removed and residual virusstock/bacterial-complex was removed from the wells by rinsing twice with MEM. Five hundred microliters of MEM was added to each well, and incubated at $37^{\circ} \mathrm{C}$ for $48 \mathrm{~h}$. One hundred and forty microliters of putatively virus-enriched media was removed from each well and extracted for viral RNA using a commercial viral RNA extraction kit as described in a previous section. Viral RNA was quantitated for TV genomic signal using a commercial RT-qPCR kit as described in a previous section.

\section{Data Analysis and Statistics}

Each experiment was repeated at least three times as independent replicates. All Ct values were converted to genomic copies. The data was then log-transformed and analyzed by one way analysis of variance. Detailed comparison was listed in legend section. $p<0.05$ was considered significant.

\section{RESULTS}

\section{Type B HBGA-Like Molecules Expression Was Detected in E. coli 086:H2}

The expression of type B HBGA-like molecules in E. coli O86:H2 was confirmed by ELISA using a panel of MAbs against HBGAlike molecules. E. coli K-12 was used as a bacterial control for non-specific binding. The OD readings from wells omitted of primary antibodies (specific for TV) were used as $\mathrm{N}$ for calculation of $\mathrm{P} / \mathrm{N}$ ratios. Only type B HBGA-like molecule was detected in E. coli $\mathrm{O} 86: \mathrm{H} 2$ with a $\mathrm{P} / \mathrm{N}$ ratio of 3.71 (Figure 1). The $\mathrm{P} / \mathrm{N}$ ratio for $E$. coli $\mathrm{K}-12$ was 1.03 . No other HBGAlike molecules were detected in E. coli O86:H2 and K-12 by using MAbs listed in Section "Materials and Methods" (data not shown).

\section{TV Bound to E. coli O86:H2 and K-12 Measured by ELISA}

Binding of TV to E. coli O86:H2 was detected by ELISA using $\mathrm{TV}$-specific polyclonal antibodies. The $\mathrm{P} / \mathrm{N}$ ratios for $E$. coli O86:H2 and K-12 were 2.23 and 1.90, respectively (Figure 2). Binding was further studied using a competition assay (Figure 2). The binding of TV to E. coli O86: $\mathrm{H} 2$ could be competitively inhibited by prior incubation of TV with free HBGA, reducing the $\mathrm{P} / \mathrm{N}$ ratio from 2.23 to $1.16(p=0.004)$. The binding of TV to $E$. coli K-12 was not inhibited by prior incubation of TV with free HBGA. In contrast to E. coli $\mathrm{O} 86: \mathrm{H} 2$, the $\mathrm{P} / \mathrm{N}$ ratio of $\mathrm{K} 12$ slightly increased from 1.89 to 2.03 after incubation of TV with

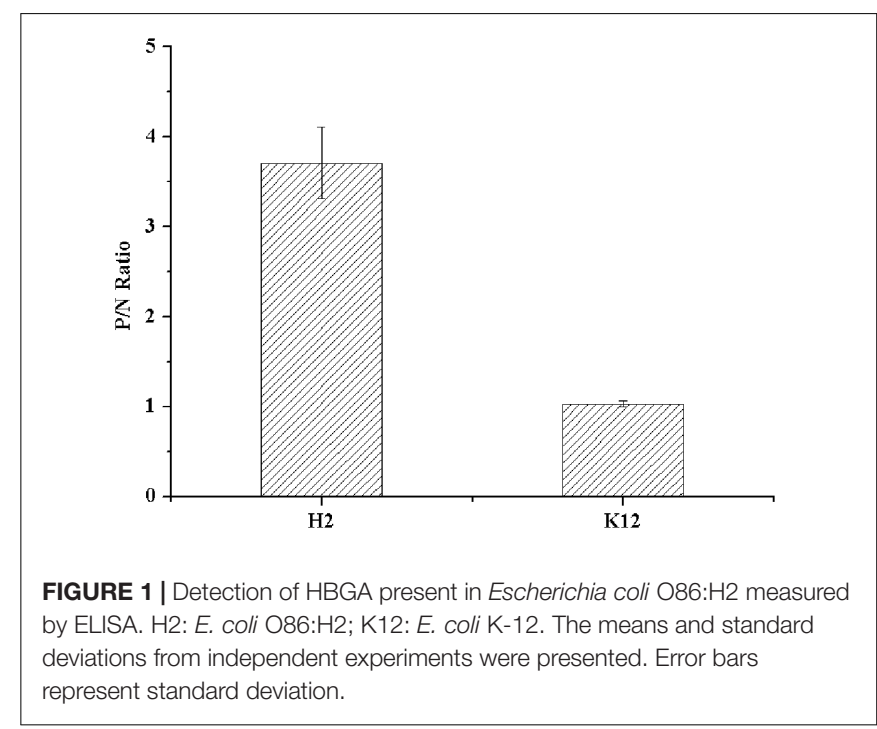




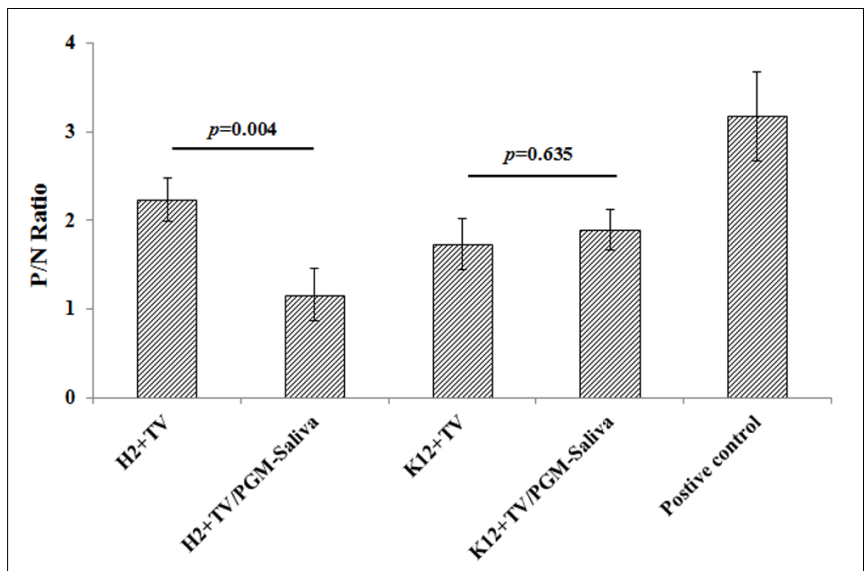

FIGURE 2 | Binding of TV to E. coli O86:H2 and K-12 measured by ELISA. H2: E. coli O86:H2; K12: E. coli K-12; TV: Tulane virus; PGM: type III porcine gastric mucin; PGM-Saliva: PGM and blood type B saliva mixture (10:1). The means and standard deviations from independent experiments were presented. Error bars represent standard deviation. H2+TV/PGM-Saliva was compared with $\mathrm{H} 2+\mathrm{TV} ; \mathrm{K} 12+\mathrm{TV} / \mathrm{PGM}-\mathrm{S}$ aliva was compared with $\mathrm{K} 12+\mathrm{TV}$ by t-test. PGM-Saliva coated plate was used as a positive control for TV capture and detection. free HBGA. Although $\mathrm{P} / \mathrm{N}$ ratio of 2.0 was used to threshold for ELISA, it is very arbitrary. Therefore, RT-qPCR was used as additional approach to determine the binding of TV on E. coli O86:H2 and E. coli K12.

\section{TV Bound to E. coli O86:H2 and K-12 Measured by RT-qPCR Assay}

Binding of TV to both E. coli O86:H2 and K-12 was indicated by RT-qPCR. TV was able to bind to E. coli O86:H2 better than to E. coli $\mathrm{K}-12$, with average Ct values of 28.21 and 31.45 , respectively. Ct values converted to amplicon copies suggest that E. coli $\mathrm{O} 86: \mathrm{H} 2$ captures roughly five times as much TV as E. coli K-12 (Figure 3). Prior incubation with free HBGA reduced the ability of $E$. coli O86:H2 to capture TV by $57 \%$ ( $p=0.008, t$-test). In contrast, prior incubation with free HBGA did not reduce the ability of E. coli K-12 to capture TV. In fact, a numerical doubling enhancement of binding was observed ( $p=0.058, t$-test).

\section{Binding of Bacteria Does Not Protect Tulane Virus from Heat-Inactivation}

TV was incubated with E. coli $086: \mathrm{H} 2$ or $\mathrm{K}-12$ at ratios of $1: 1$ and $100: 1$, and heat-denatured at partial $\left(56^{\circ} \mathrm{C}\right.$ for $\left.10 \mathrm{~min}\right)$ and full $\left(56^{\circ} \mathrm{C}\right.$ for $\left.30 \mathrm{~min}\right)$ inactivation conditions (Figure 4). The amplification of TV in LLC-MK2 cells was measured at $48 \mathrm{~h}$ post-infection by RT-qPCR assay. Incubation with bacteria reduced the attachment of TV to host cell culture, in-turn reducing its replication (Figure 4A). In the absence of bacteria, the TV titer was $1.72 \times 10^{6}$ genomic copy after $48 \mathrm{~h}$ postinfection. The viral titers were $6.81 \times 10^{5} / \mathrm{ml}(p=0.012)$, $6.01 \times 10^{5} / \mathrm{ml}(p=0.010), 4.62 \times 10^{5} / \mathrm{ml}(p=0.002)$, and $4.32 \times 10^{5} / \mathrm{ml}(p=0.002)$ for TV w/O86:H2 at $1: 1$, TV w/K12 at 1:1, TV w/O86:H2 at 100:1, and TV w/K-12 at 100:1,

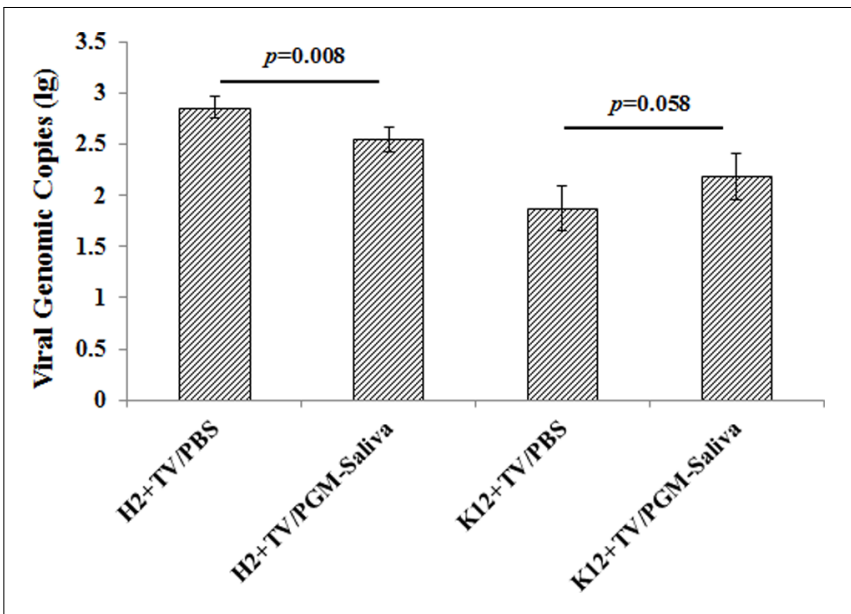

FIGURE 3 | Binding of Tulane virus to E. coli O86: $\mathrm{H} 2$ and $\mathrm{K}-12$ measured by RT-qPCR assay. H2: E. coli O86:H2; K12: E. coli K-12; TV: Tulane virus; PGM: type III porcine gastric mucin; PGM-Saliva: PGM and blood type B saliva mixture (10:1). The means and standard deviations from independent experiments were presented. Error bars represent standard deviation. $\mathrm{H} 2+$ TV/PGM-Saliva was compared with H2+TV/PBS; K12+TV/PGM-Saliva was compared with $\mathrm{K} 12+\mathrm{TV} / \mathrm{PBS}$ by $t$-test.

respectively (Holm-Sidak method). Binding to E. coli O86:H2 or K-12 did not seem to confer to TV any protection against heatdenaturation. There was no significant difference in viral titers in the presence of bacteria and absence of bacteria when TV was heat-inactivated ( $p=0.83$, Kruskal-Wallis one way analysis of variance on ranks). Heat-denaturation at partial inactivation conditions $\left(56^{\circ} \mathrm{C}\right.$ for $\left.10 \mathrm{~min}\right)$ of $\mathrm{TV}$ and TV-bacteria complex produced viral genomic copies of $1.18 \times 10^{4} / \mathrm{ml}, 2.10 \times 10^{3} / \mathrm{ml}$ $(p=0.32), 1.46 \times 10^{4} / \mathrm{ml}(p=1.0), 7.89 \times 10^{3} / \mathrm{ml}(p=0.96)$, and $3.16 \times 10^{4} / \mathrm{ml}(p=0.81)$ for TV, TV w/O86:H2 at 1:1, TV w/K-12 at 1:1, TV w/O86:H2 at 100:1, and TV w/K-12 at $100: 1$, respectively ( $t$-test, $p>0.05$ ). Heat denaturation at partial inactivation conditions produced a similar reduction in viral replication regardless of the presence of bacterial binding, with loss percentages of 99.03, 99.42, 96.32, 96.10, 98.88\% for TV, TV w/O86:H2 at 1:1, TV w/O86:H2 at 100:1, TV w/K-12 at 1:1, and in TV w/K-12 at 100:1, respectively (Figure 4B). There was no statistical difference among groups in the presence of bacteria and absence of bacteria ( $p=0.367$, Brown-Forsythe). Heat denaturation at full inactivation conditions $\left(56^{\circ} \mathrm{C}\right.$ for $\left.30 \mathrm{~min}\right)$ produced total eradication of viral replication regardless of the presence of bacterial binding, and produced no detectable Ct values.

\section{DISCUSSION}

The interaction between HuNoVs and HBGAs has been demonstrated (Huang et al., 2003, 2005; Hutson et al., 2004). However, the role of HBGA in the viral replication cycle remains unclear. HBGAs have been considered putative viral receptor or co-receptors. HuNoV's ability to bind to various HBGAs is an adaptation that might have played an important role in viral 

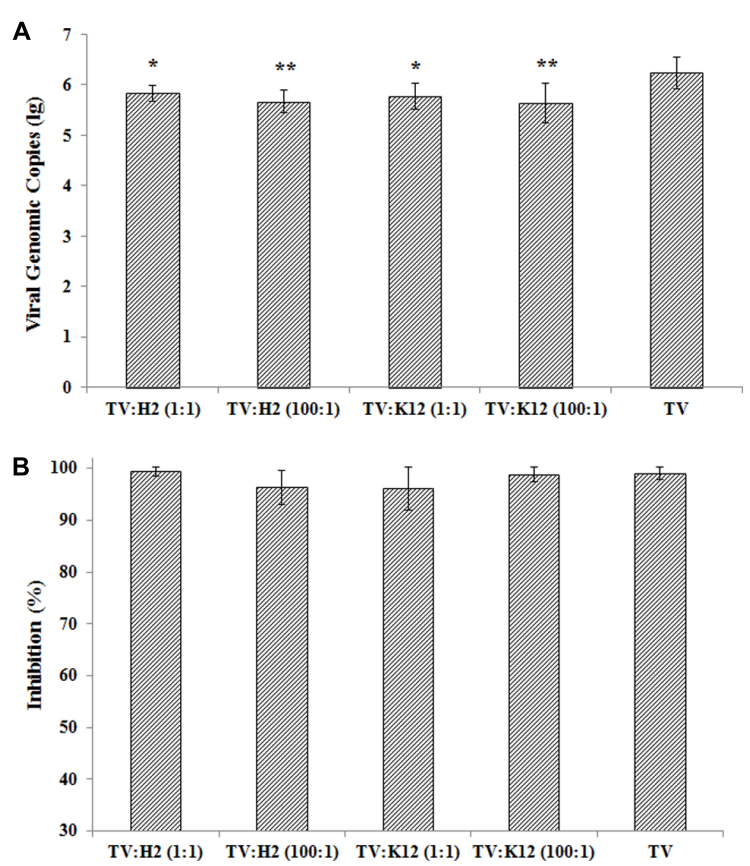

FIGURE 4 | (A) TV replication in the presence of bacteria and absence of bacteria. $\mathrm{H} 2$ : E. coli O86:H2; K12: E. coli K-12; TV: Tulane virus; ratio of TV to bacteria was listed in parenthesis. Error bars represent standard deviation. Groups of bacteria-virus-complex were compared with TV by one way analysis of variance (Brown-Forsythe method). ${ }^{*} p<0.05,{ }^{* *} p<0.01$. (B) Inhibition of TV replication under heat-inactivation. The means and standard deviations from independent experiments were presented. Inhibition of viral replications after treatment of $56^{\circ} \mathrm{C}$ for 10 min calculated by the formula: 1-(viral genomic copy with treatment divided by viral genomic copy without treatment) \%. One way analysis of variance (Kruskal-Wallis method) was used for statistical analysis of log-transformed data $(p=0.832)$ and Brown-Forsythe method was used to analysis \% inhibition $(p=0.367)$. No significant difference among all groups tested in both methods.

evolution (Singh et al., 2015a,b). HBGA-like moieties are present on the surface of some enteric bacteria (Springer et al., 1961; Yi et al., 2006; Miura et al., 2013; Li et al., 2015). Type H HBGAlike molecules found in Enterobacter cloacae could specifically bind HuNoV (Miura et al., 2013). Li et al. (2015) tested 11 bacterial strains for the presence of HBGA-like molecules and found expression in 8, with 5 strains capable of binding $\mathrm{HuNoV}$ rVLPs (recombinant VLPs). Li et al. (2015) further demonstrated that HuNoV rVLPs could be protected from acute heat stress by being bound to HBGA-like molecules-expressing bacteria ( $\mathrm{Li}$ et al., 2015). This result was consistent with a previous report observing that cell attachment and environmental stability of poliovirus was enhanced by the binding of bacterial surface polysaccharides (Robinson et al., 2014). It needs to be noted that the Robinson study was conducted with viable poliovirus, while the Li study was conducted with VLPs rather than viable viruses. The measure of resistance to heat-stress was the persistence of the ability for VLPs or VLP-bacteria complex to bind to HBGAcoated wells after heat-denaturation. Therefore, there has been no direct evidence showing the HuNoVs would be protected against heat stress by the binding of HBGA-like molecules-expressing bacteria. In this study, we used TV as a surrogate to test the impact of HBGA-like molecules-expressing bacteria on viral inactivation by heat denaturation.

We demonstrated that type B HBGA-like molecules were expressed in E. coli $\mathrm{O} 86: \mathrm{H} 2$, but not in E. coli $\mathrm{K}-12$ which shares a similar genetic background with O86:H2 except for HBGAlike molecules expression. We found that TV could bind to both E. coli $\mathrm{O} 86: \mathrm{H} 2$ and $\mathrm{K}-12$, with $\mathrm{O} 86: \mathrm{H} 2$ manifesting more binding capacity. In addition, TV binding to intact bacterial cells was also suggested by RT-qPCR assay. The binding of TV to E. coli O86:H2 was partially HBGA-like molecules-mediated, as competitive binding from free HBGA could significantly reduce the quantifiable TV binding through both ELISA and RT-qPCR quantitation methods. In contrast, binding of TV to E. coli K-12 was nor reduced but slightly enhanced by competition from free HBGA. In conjunction with the observation through RT-qPCR that binding of TV to E. coli O86:H2 could not be completely inhibited by free HBGA, we believe we have observed the manifestation of both HBGA-like molecules-mediated and a yet-to-be-fully-characterized TV binding effects. Only this yetto-be-fully-characterized TV binding was manifested by E. coli K12. It is possible that molecules other than HBGA-like molecules present in both E. coli $\mathrm{O} 86: \mathrm{H} 2$ and $\mathrm{K}-12$ are involved in the binding of TV. A recent report indicated that HuNoVs were able to bind to 10 bacteria strains with high efficiency (five Gram-positive and five Gram-negative strains) from human gut microbiota (Almand et al., 2017). GI and GII HuNoVs could bind to all 10 strains and TV could bind to 5 strains in this study. The viruses could be found in bacterial outer cell membrane, pili, or both by TEM (Almand et al., 2017). The interaction between these bacterium and HuNoVs or TV were considered specific as Turnip Crinkle virus did not bind to these bacterium (Almand et al., 2017). However, there was no evident that these tested bacterium all expressed HBGA-like molecules. We propose that $\mathrm{HuNoV}$ and TV could bind to molecules other than HBGA-like molecules. Murakami reported that binding of HuNoVs to human intestinal epithelial cells was independent of HBGA (Murakami et al., 2013). Tamura reported that GI VLPs could bind to a 105-kilodalton cellular binding protein (Tamura et al., 2000) and GII HuNoV could bind to heparan sulfate proteoglycan associated with the cellular membrane (Tamura et al., 2004). Gandhi et al. (2010) reported that GI VLPs could bind to lettuce by molecules other than HBGA. It has been reported that TV could use multiple receptors, including type A, type B and sialic acids (Tan et al., 2015; Zhang et al., 2015). Currently, we are in the process of identifying in bacteria participants other than HBGA-like molecules responsible for HuNoVs binding.

The infectivity of a culturable virus was traditionally determined by plaque assay and/or $50 \%$ tissue culture infectious dose $\left(\mathrm{TCID}_{50}\right)$ assay, both of which are time-consuming and labor-intensive. It requires at least 5 days for optimal results. Recently, we developed the CMA-RT-qPCR as an alternative method to rapidly determine the infectivity of TV (Xu et al., 2015). With this assay, the input viral genomic signal could be detected at $6 \mathrm{~h}$ post-infection, became undetectable at $12 \mathrm{~h}$ postinfection, and the newly amplified viral genomic signal could be 
detectable at $24 \mathrm{~h}$ post-infection. Previously, we demonstrated that this method was comparable to TCID $_{50}$ in determination of inactivation status of TV caused by various inactivation conditions including heat, chlorine, and UV-inactivation (Xu et al., 2015). Therefore, we used this method to determine the infectivity of the virus in this study.

The effect of the presence of bacteria on norovirus viral infectivity has never tested. It has been reported that the presence of enteric bacteria could enhance rotavirus binding/entry to host cells (Uchiyama et al., 2014). In this study, we demonstrated incubation with bacteria slightly reduced the attachment/replication of TV in LLC-MK2 cells. However, we found that binding of neither E. coli O86:H2 or K-12 conferred any protection to TV from inactivation by heat-denaturation. This finding is contrary to the implications of a prior report by $\mathrm{Li}$ et al. (2015). However, significant differences between these two studies may explain the varying conclusions, including the different strains of bacteria used in the studies, viral components, and targets for the end results. In the Li et al. (2015) study, HuNoV rVLPs were utilized instead of infectious viruses. As such, the only possible quantitation was that of binding (and loss-of-such) between rVLPs and HBGA-like molecules, but not the loss of infectivity. In this study, we quantitated viral replication as the indicator of viral infectivity, which inturn is the indicator of resistance to heat-denaturation. We were able to achieve a more-direct demonstration that the binding of TV to bacteria regardless of HBGA-like molecules

\section{REFERENCES}

Almand, E. A., Moore, M. D., Outlaw, J., and Jaykus, L. A. (2017). Human norovirus binding to select bacteria representative of the human gut microbiota. PLOS ONE 12:e0173124. doi: 10.1371/journal.pone.0173124

Cannon, J. L., Papafragkou, E., Park, G. W., Osborne, J., Jaykus, L. A., and Vinje, J. (2006). Surrogates for the study of norovirus stability and inactivation in the environment: aA comparison of murine norovirus and Feline calicivirus. J. Food Prot. 69, 2761-2765.

Farkas, T., Cross, R. W., Hargitt, E. III, Lerche, N. W., Morrow, A. L., and Sestak, K. (2010). Genetic diversity and histo-blood group antigen interactions of rhesus enteric caliciviruses. J. Virol. 84, 8617-8625. doi: 10.1128/JVI.00630-10

Farkas, T., Sestak, K., Wei, C., and Jiang, X. (2008). Characterization of a rhesus monkey calicivirus representing a new genus of Caliciviridae. J. Virol. 82, 5408-5416. doi: 10.1128/JVI.00070-08

Gandhi, K., Mandrell, R., and Tian, P. (2010). Binding of virus-like particles of Norwalk virus to romaine lettuce veins. Appl. Environ. Microbiol. 76, 7997-8003. doi: 10.1128/AEM.01566-10

Gary, G. W., Anderson, L. J., Keswick, B. H., Johnson, P. C., DuPont, H. L., Stine, S. E., et al. (1987). Norwalk virus antigen and antibody response in an adult volunteer study. J. Clin. Microbiol. 25, 2001-2003.

Hardy, M. E. (2005). Norovirus protein structure and function. FEMS Microbiol. Lett. 253, 1-8. doi: 10.1016/j.femsle.2005.08.031

Harrington, P. R., Lindesmith, L., Yount, B., Moe, C. L., and Baric, R. S. (2002). Binding of Norwalk virus-like particles to $\mathrm{ABH}$ histo-blood group antigens is blocked by antisera from infected human volunteers or experimentally vaccinated mice. J. Virol. 76, 12335-12343.

Huang, P., Farkas, T., Marionneau, S., Zhong, W., Ruvoen-Clouet, N., Morrow, A. L., et al. (2003). Noroviruses bind to human ABO, Lewis, and secretor histo-blood group antigens: identification of 4 distinct strain-specific patterns. J. Infect. Dis. 188, 19-31. doi: 10.1086/375742

Huang, P., Farkas, T., Zhong, W., Tan, M., Thornton, S., Morrow, A. L., et al. (2005). Norovirus and histo-blood group antigens: demonstration of a wide spectrum of strain specificities and classification of two major binding groups expression did not provide protection to the virus against heatdenaturation.

\section{AUTHOR CONTRIBUTIONS}

PT and QL designed the experiments. QL carried out the experiments with assistance from DW, DY, LS, and PT. PT and QL conducted statistical analysis. PT and QL wrote the paper. DY modified the paper. All authors reviewed the results, made substantial contributions and approved the final version of the manuscript.

\section{FUNDING}

The work was supported by USDA Agricultural Research Service CRIS project 5325-42000-050-06R and Grant 31772078 from National Natural Science Foundation of China. USDA is an equal opportunity provider and employer.

\section{ACKNOWLEDGMENT}

The authors would like to thank Dr. P. Wang (Department of Chemistry, Georgia State University, Atlanta, GA, United States) for providing E. coli O86:H2.

among multiple binding patterns. J. Virol. 79, 6714-6722. doi: 10.1128/JVI.79. 11.6714-6722.2005

Hutson, A. M., Atmar, R. L., and Estes, M. K. (2004). Norovirus disease: changing epidemiology and host susceptibility factors. Trends Microbiol. 12, 279-287. doi: 10.1016/j.tim.2004.04.005

Jiang, X., Wang, M., Wang, K., and Estes, M. K. (1993). Sequence and genomic organization of Norwalk virus. Virology 195, 51-61. doi: 10.1006/viro.1993.1345

Jones, M. K., Watanabe, M., Zhu, S., Graves, C. L., Keyes, L. R., Grau, K. R., et al. (2014). Enteric bacteria promote human and mouse norovirus infection of B cells. Science 346, 755-759. doi: 10.1126/science.1257147

Karst, S. M., and Wobus, C. E. (2015). A working model of how noroviruses infect the intestine. PLOS Pathog. 11:e1004626. doi: 10.1371/journal.ppat.10 04626

Kuss, S. K., Best, G. T., Etheredge, C. A., Pruijssers, A. J., Frierson, J. M., Hooper, L. V., et al. (2011). Intestinal microbiota promote enteric virus replication and systemic pathogenesis. Science 334, 249-252. doi: 10.1126/science.1211057

Li, D., Breiman, A., le Pendu, J., and Uyttendaele, M. (2015). Binding to histoblood group antigen-expressing bacteria protects human norovirus from acute heat stress. Front. Microbiol. 6:659. doi: 10.3389/fmicb.2015.00659

Miura, T., Sano, D., Suenaga, A., Yoshimura, T., Fuzawa, M., Nakagomi, T., et al. (2013). Histo-blood group antigen-like substances of human enteric bacteria as specific adsorbents for human noroviruses. J. Virol. 87, 9441-9451. doi: 10.1128/JVI.01060-13

Murakami, K., Kurihara, C., Oka, T., Shimoike, T., Fujii, Y., Takai-Todaka, R., et al. (2013). Norovirus binding to intestinal epithelial cells is independent of histo-blood group antigens. PLOS ONE 8:e66534. doi: 10.1371/journal.pone. 0066534

Parrino, T. A., Schreiber, D. S., Trier, J. S., Kapikian, A. Z., and Blacklow, N. R. (1977). Clinical immunity in acute gastroenteritis caused by Norwalk agent. N. Engl. J. Med. 297, 86-89. doi: 10.1056/NEJM197707142970204

Robinson, C. M., Jesudhasan, P. R., and Pfeiffer, J. K. (2014). Bacterial lipopolysaccharide binding enhances virion stability and promotes environmental fitness of an enteric virus. Cell Host Microbe 15, 36-46. doi: 10.1016/j.chom.2013.12.004 
Singh, B. K., Koromyslova, A., Hefele, L., Gurth, C., and Hansman, G. S. (2015a). Structural evolution of the emerging 2014-2015 GII.17 noroviruses. J. Virol. 90, 2710-2715. doi: 10.1128/JVI.03119-15

Singh, B. K., Leuthold, M. M., and Hansman, G. S. (2015b). Human noroviruses' fondness for histo-blood group antigens. J. Virol. 89, 2024-2040. doi: 10.1128/ JVI.02968-14

Springer, G. F., Williamson, P., and Brandes, W. C. (1961). Blood group activity of Gram-negative bacteria. J. Exp. Med. 113, 1077-1093.

Stuart, A. D., and Brown, T. D. (2007). Alpha2,6-linked sialic acid acts as a receptor for Feline calicivirus. J. Gen. Virol. 88(Pt 1), 177-186. doi: 10.1099/vir.0.82158-0

Tamura, M., Natori, K., Kobayashi, M., Miyamura, T., and Takeda, N. (2000). Interaction of recombinant norwalk virus particles with the 105kilodalton cellular binding protein, a candidate receptor molecule for virus attachment. J. Virol. 74, 11589-11597. doi: 10.1128/JVI.74.24.11589-11597. 2000

Tamura, M., Natori, K., Kobayashi, M., Miyamura, T., and Takeda, N. (2004). Genogroup II noroviruses efficiently bind to heparan sulfate proteoglycan associated with the cellular membrane. J. Virol. 78, 3817-3826. doi: 10.1128/ JVI.78.8.3817-3826.2004

Tan, M., and Jiang, X. (2005). Norovirus and its histo-blood group antigen receptors: an answer to a historical puzzle. Trends Microbiol. 13, 285-293. doi: 10.1016/j.tim.2005.04.004

Tan, M., Wei, C., Huang, P., Fan, Q., Quigley, C., Xia, M., et al. (2015). Tulane virus recognizes sialic acids as cellular receptors. Sci. Rep. 5:11784. doi: 10.1038/ srep11784

Taube, S., Perry, J. W., Yetming, K., Patel, S. P., Auble, H., Shu, L., et al. (2009). Ganglioside-linked terminal sialic acid moieties on murine macrophages function as attachment receptors for murine noroviruses. J. Virol. 83, 4092-4101. doi: 10.1128/JVI.02245-08

Tian, P., Yang, D., Quigley, C., Chou, M., and Jiang, X. (2013). Inactivation of the Tulane virus, a novel surrogate for the human norovirus. J. Food Prot. 76, 712-718. doi: 10.4315/0362-028X.JFP-12-361

Uchiyama, R., Chassaing, B., Zhang, B., and Gewirtz, A. T. (2014). Antibiotic treatment suppresses rotavirus infection and enhances specific humoral immunity. J. Infect. Dis. 210, 171-182. doi: 10.1093/infdis/jiu037
Wang, D., Xu, S., Yang, D., Young, G. M., and Tian, P. (2014). New in situ capture quantitative (real-time) reverse transcription-PCR method as an alternative approach for determining inactivation of Tulane virus. Appl. Environ. Microbiol. 80, 2120-2124. doi: 10.1128/AEM.04036-13

Wang, M., Rong, S., Tian, P., Zhou, Y., Guan, S., Li, Q., et al. (2017). Bacterial surface-displayed GII.4 human norovirus capsid proteins bound to HBGA-like molecules in Romaine lettuce. Front. Microbiol. 8:251. doi: 10.3389/fmicb.2017. 00251

Wobus, C. E., Thackray, L. B., and Virgin, H. W. (2006). Murine norovirus: a model system to study norovirus biology and pathogenesis. J. Virol. 80, 5104-5112. doi: 10.1128/JVI.02346-05

Xi, J. N., Graham, D. Y., Wang, K. N., and Estes, M. K. (1990). Norwalk virus genome cloning and characterization. Science 250, 1580-1583. doi: 10.1126/ science. 2177224

Xu, S., Wang, D., Yang, D., Liu, H., and Tian, P. (2015). Alternative methods to determine infectivity of Tulane virus: a surrogate for human norovirus. Food Microbiol. 48, 22-27. doi: 10.1016/j.fm.2014.12.004

Yi, W., Bystricky, P., Yao, Q., Guo, H., Zhu, L., Li, H., et al. (2006). Two different $\mathrm{O}$-polysaccharides from Escherichia coli $\mathrm{O} 86$ are produced by different polymerization of the same O-repeating unit. Carbohydr. Res. 341, 100-108. doi: 10.1016/j.carres.2005.11.001

Zhang, D., Huang, P., Zou, L., Lowary, T. L., Tan, M., and Jiang, X. (2015). Tulane virus recognizes the A type 3 and B histo-blood group antigens. J. Virol. 89, 1419-1427. doi: 10.1128/JVI.02595-14

Conflict of Interest Statement: The authors declare that the research was conducted in the absence of any commercial or financial relationships that could be construed as a potential conflict of interest.

Copyright (c) 2017 Li, Wang, Yang, Shan and Tian. This is an open-access article distributed under the terms of the Creative Commons Attribution License (CC BY). The use, distribution or reproduction in other forums is permitted, provided the original author(s) or licensor are credited and that the original publication in this journal is cited, in accordance with accepted academic practice. No use, distribution or reproduction is permitted which does not comply with these terms. 